\title{
Effectiveness of a Self-Foot-Care Educational Program for Prevention of Diabetic Foot Disease
}

\author{
Kayo Yokota1, Yuko Hayashi², Junichi Kurata ${ }^{3}$, Atsuyo Fujita ${ }^{4}$ \\ ${ }^{1}$ Graduate School of Nursing, Osaka Medical College, Osaka, Japan \\ ${ }^{2}$ Faculty of Nursing, Kansai Medical College, Osaka, Japan \\ ${ }^{3}$ Department of Mechanical Engineering, Kansai University, Osaka, Japan \\ ${ }^{4}$ Seichokai Social Medical Corporation, Hannan Municipal Hospital, Osaka, Japan \\ Email: yokota29@iris.eonet.ne.jp
}

How to cite this paper: Yokota, K., Hayashi, Y., Kurata, J. and Fujita, A. (2019) Effectiveness of a Self-Foot-Care Educational Program for Prevention of Diabetic Foot Disease. Health, 11, 9-19.

https://doi.org/10.4236/health.2019.111002

Received: December 3, 2018

Accepted: January 5, 2019

Published: January 8, 2019

Copyright (c) 2019 by author(s) and Scientific Research Publishing Inc. This work is licensed under the Creative Commons Attribution International License (CC BY 4.0).

http://creativecommons.org/licenses/by/4.0/

\begin{abstract}
Objective: To verify the effectiveness of a "self-foot-care educational program (SFCEP)" for prevention of type 2 diabetes foot disease. Methods: A single-center, randomized and controlled trial was conducted. Fifty-five patients with type $2 \mathrm{DM}, 40$ - 75 years of age who were asked to return for a follow-up hospital visit, were allocated to either an SFCEP group $(n=29)$ or a conventional education program (CEP) group $(n=26)$. Both of the groups were given foot-care education, monthly for four times in the SFCEP group and in the CEP group one time only by a printed leaflet. The two groups had no statistically significant differences in patient background of the type 2 diabetes history. We evaluated removal rate of skin debris, and the symptoms and conditions of the feet. Results: Between the SFCEP and CEP there were significant differences in removal rate of skin debris $(p<0.05)$, and the conditions of the feet, dryness $(p<0.001)$, horny tissue $(p<0.001)$ and peripheral coldness $(p<0.05)$. The SDCEP was significantly better than the CEP. Conclusion: This study strongly suggests the effectiveness of SFCEP in preventing the occurrence or worsening of diabetic foot diseases.
\end{abstract}

\section{Keywords}

Patients with Type 2 Diabetes, Self-Foot-Care Educational Program,

Prevention of Diabetic Foot Disease, Randomized Controlled Trial

\section{Introduction}

Diabetic foot disease, a complication of type 2 diabetes mellitus (DM), may cause foot ulcers and gangrene when left untreated, and eventually lead to foot 
amputation, affecting the quality of life (QOL) of patients. Cases with toe and lower limb amputation are frequent in patients at high risk of foot disease [1]. It is reported that many of these patients lack knowledge and awareness of foot-care [2].

In foot-care education for patients with type $2 \mathrm{DM}$, it is also known that there is no short- or long-term improvement if the education is only giving patients objective information of the ailment, and that there is no long-term improvement if only knowledge of diabetes and foot-care skills is provided [3].

A previous intervention study of foot-care education reports that many of the educational programs are provided as one-to-one instruction, and cover foot risk assessment, instruction using foot-care models, DVD, and printed leaflets, instruction in how the patients check their own feet, practical instruction in foot-care, instruction incorporating suggestions for improvements in standing position, and walking ability, and follow-up by telephone and home [4]. The effects of the educational programs have been evaluated in terms of foot-care knowledge, self-care behavior, QOL, ulcer and foot amputation rates, and knowledge of foot-care [5] [6] [7].

It is important to provide foot-care education in the early stage after diagnosis of type $2 \mathrm{DM}$ because there is a limited effect when patients have reached the high risk stage of the condition. For this reason, it is important to provide preventive foot-care education [4]. Further, the importance of education which emphasizes self-foot-care on enabling improvements in patient awareness of foot-care, and on becoming able to conduct the care voluntarily and continuously has been reported [6].

These findings suggest the necessity to provide foot-care education that improves the awareness of the prevention of diabetic foot disease, and enables patients to conduct appropriate foot-care with confidence and also routinely, as well as provides knowledge and skills.

Previous studies on the education of patients with chronic diseases have reported that self-foot-care educational programs for prevention of diabetic foot disease which incorporate self-monitoring and feedback show educational effects such as improvements in symptoms and changes in behaviors [8] [9] [10] [11]. Based on this, the authors have developed a "self-foot-care educational program (SFCEP)" for prevention of type 2 diabetic foot disease of DM patients, which incorporates self-foot-care and self-monitoring as an element in the foot-care education to improve the patients' awareness of diabetic foot disease so that patients will be able to conduct foot-care routinely, and change their behaviors to prevent the occurrence of the disease. This study aims to provide education for patients with type 2 DM using the above educational program (SFCEP), and verify the effectiveness of the program by a randomized controlled trial (RCT).

\section{Purpose}

This study aims to develop a "self-foot-care educational program (SFCEP)" that 
encourages patients with type $2 \mathrm{DM}$ to change patient behaviors to prevent them from developing and causing deterioration in diabetic foot disease, and verify the effectiveness of the program.

\section{Methods}

\subsection{Hypothesis of the Study}

We hypothesized that the SFCEP that incorporates self-foot-care and a self-monitoring to encourage patients with type $2 \mathrm{DM}$ to prevent the disease will improve in the removal rate of skin debris, and improve the symptoms and conditions of the feet, contributing to long-term prevention of diabetic foot disease.

\subsection{Operational Definition}

- Diabetic foot disease: a foot disease developed and progressing due to diabetic neuropathy, peripheral vascular disorders, skin damage, and deterioration of body defense functions.

- Self-foot-care: conducting foot care by the patients themselves by observing the symptoms of their feet, noticing changes, and deciding on appropriate foot-care.

- Self-monitoring: noticing changes in the feet through a record of observed and measured conditions and perceptions of the feet; as well as behaviors, feelings, and thoughts related to the feet.

- Removal rate of skin debris: rate of the entire foot area covered by skin debris including the areas between toes.

\subsection{Study Participants and Period}

The participants are outpatients of two foot-care clinics of regional medical support hospitals in Osaka Prefecture in Japan, who were diagnosed with type 2 diabetes mellitus (DM). Inclusion criteria included: 1) outpatients aged 40 to 75 who visited the clinic monthly, 2) participation to start within 5 years of the diagnosis of type 2 DM as of July 2016,3) receiving basic instruction in type 2 DM (diabetic pathology, complications, diet therapy, exercise therapy, and medication), 4) absence of cognitive impairment, mental disorders, details of severe complications, and 5) being independent in daily life activities, and excluding patients not able to read and write letters due to diabetic retinopathy. The research period was from September of 2016 to June of 2017.

\subsection{Procedures of the Study}

The study design has an intervention approach by RCT to evaluate the effectiveness of a "self-foot-care educational program (SFCEP)". The participants were allocated to either of a self-foot-care educational intervention group (SFCEP group) or to a control group which was provided with education only by a printed leaflet (CEP group).

1) Participant allocation 
We requested the attending physician of the participating clinics to introduce patients meeting the inclusion criteria, and obtained consent for participation after providing patients with a detailed explanation of the study participation. Matching the participants so that both SFCEP and CEP groups had the same number of males and females, the participants were randomly allocated to the two groups by gender in the order of obtaining consent to participate. We used envelopes that contained an identifying card in designating either group to randomly allocate the participants to the groups. Assuming $\alpha$ (significance) $=0.05$ and $1-\beta$ (power) $=0.8$, we performed the variance analysis by repeated measurements, and determined the sample size as 29 . Considering the possibility of participants who will discontinue in the middle, we assumed 30 people for both intervention and control groups. To avoid influence on the CEP group, we decided to provide the education program to the two groups on different days of the week.

2) Self-foot-care educational program (SFCEP)

Based on a literature review [8] [12] and clinical experience, a "self-foot-care educational program (SFCEP)" was developed. This program is comprised of the following two sections: "self-foot-care", which aims to provide knowledge and skills for patients so that they can conduct foot-care by themselves, and "self-monitoring", which aims to encourage patients to evaluate symptoms of their feet and behavior, and to notice changes in the feet by keeping a record of observations and measurements of the feet. In the first visit of the educational program the researcher explained about the treatment and complications with diabetes, and instructed in foot-care (how to observe, assess, and care for the feet), using a printed leaflet created by the researcher. In the second to fourth visits, the researcher confirmed the knowledge of participants of self-foot-care incorporating how it was practiced, provided details of skills (foot observation and care, shoes and socks, foot exercises, and massage, and how to moisturize feet), and conducted self-monitoring utilizing a self-foot-care diary. The participants were asked to write about the foot conditions and symptoms, foot-care and measurements (tuning fork test, monofilament, pulsation of the dorsal artery of the foot), examination data, and review of the items included and noted in the self-foot-care diary.

3) Implementation of the educational program

a) SFCEP group

Based on the SFCEP (Self-foot-care educational program), the researcher provided four sessions of self-foot-care education individually to each participant. In the first session, we provided general knowledge of diabetes and foot care using the printed leaflet, and instructed in how to use the self-foot-care diary. From the second session onward, we instructed participants one, two, and three months after the first session so that they could make monthly evaluations of the changes in the feet and foot-care, objectively by noting the results of the foot assessment and the data related to diabetes while referring to the previous records of foot conditions, symptoms, and details of foot-care they had previously noted 
in the diary. Next, we evaluated the foot-care conducted by the patients to ensure that they have mastered the activities of appropriate foot-care. In this manner, we repeated the feedback of evaluation and instruction by explaining what is improving and what problems there may be. The time required for a session was 30 minutes per participant.

b) CEP group

In the CEP group, the researcher only provided knowledge using the printed leaflet on diabetes and foot-care at the first visit. The time required for a session here was also 30 minutes per participant.

\subsection{Data Collection}

Information of demographic characteristics was collected from the medical records by physicians and nurses. The effectiveness of the education was evaluated by the removal rate of skin debris and the symptoms and conditions of the feet. To evaluate the removal rate of skin debris of both groups, we photographed the feet after washing in hot water and with soap 6 months after the start of intervention. A fluorescent agent was applied to the feet before they were photographed in a box in a darkroom environment using black light. The researcher inspected and evaluated the symptoms and conditions of the feet for dryness, horny tissue, calluses, deep cuts/ingrown toenails, and ringworms of the participants of both groups before and at 6 months after the intervention. For the coldness, the researcher examined with the hands. In addition, the researcher evaluated the symptoms and conditions of the feet referring to the self-foot-care diary of the participants.

\subsection{Data Analysis}

We performed a chi-square test and a t-test to compare the demographic data of the two groups. In the image processing of the feet, as shown in Figure 1, with the area for analysis based on the lengths of the second and fourth toes, the length of the gap between the first and second toes (a), and that between the fourth and fifth toes (b) were measured as the length of the toes. A straight line

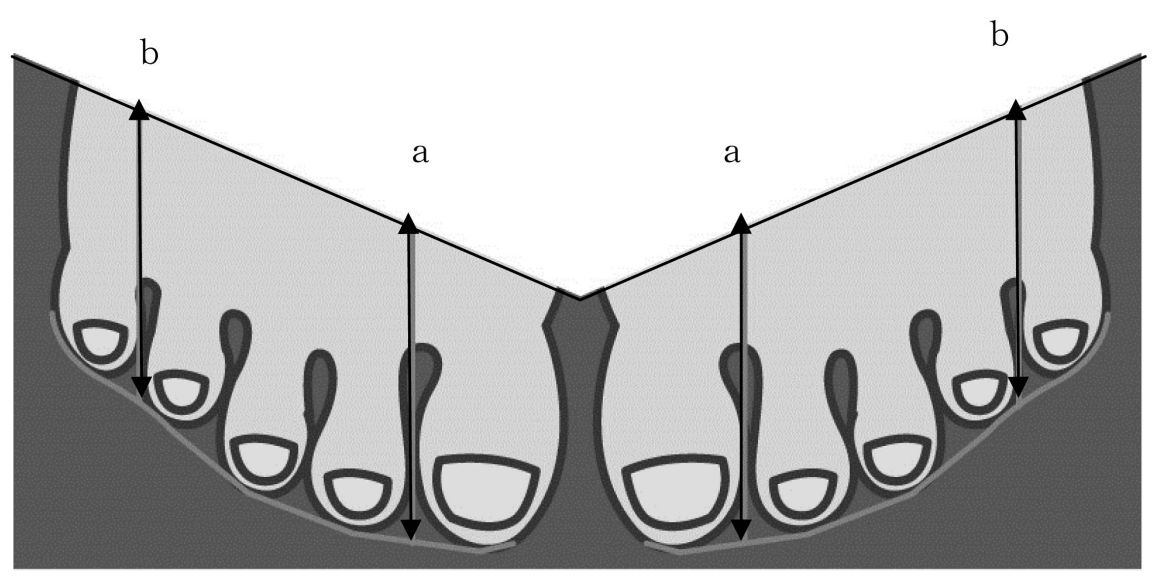

Figure 1. Image for details of the measurement area determination 
between the two points ((a) and (b)) was used as the boundary of the area for the analysis. After image processing, we calculated the removal rate of skin debris, and performed a t-test. The symptoms and conditions of the feet were also evaluated by a chi-square test.

\subsection{Ethical Considerations}

We explained the outline of the study to the participants in writing, and the consent of participation was considered to be obtained when the patients signed the consent form for the participation. For the CEP group, we provided the information about the SFCEP according to the preference of the participants. This study was approved by the ethics review committee of the Osaka Medical University (Nursing-45-1941).

\section{Results}

\subsection{Background of Participants}

There were 29 participants in the intervention (SFCEP) group and 26 in the control (CEP) group. In the SFCEP group, one participant transferred to another facility, and dropped out after three months. In the SEP group three participants who transferred to another facility or did not appear at the outpatient consultation and dropped out after three months, and one after 6 months. Table 1 shows

Table 1. Background of the participants at the time of the start of the intervention.

\begin{tabular}{|c|c|c|c|c|}
\hline & & $\begin{array}{c}\text { Intervention } \\
(\mathrm{n}=29) \\
\text { Mean } \pm \mathrm{SD} \\
\mathrm{n}(\%)\end{array}$ & $\begin{array}{c}\text { Control } \\
(\mathrm{n}=26) \\
\text { Mean } \pm \text { SD } \\
\mathrm{n}(\%)\end{array}$ & $\mathrm{p}$ value \\
\hline Age & & $60.0 \pm 9.3$ & $59.5 \pm 9.3$ & $0.847 \mathrm{~ns}^{\mathrm{a}}$ \\
\hline Male & & $17(58.6)$ & $14(53.8)$ & \multirow{2}{*}{$0.468 \mathrm{~ns}^{\mathrm{b}}$} \\
\hline Female & & $12(41.4)$ & $12(46.2)$ & \\
\hline \multirow[t]{4}{*}{ Condition of diabetes } & Duration of disease (years) & $2.2 \pm 1.4$ & $2.0 \pm 1.1$ & $0.484 n s^{a}$ \\
\hline & HbAlc (\%) & $7.5 \pm 1.5$ & $7.5 \pm 1.7$ & $0.935 \mathrm{~ns}^{\mathrm{a}}$ \\
\hline & Weight (kg) & $65.7 \pm 12.4$ & $65.0 \pm 24.4$ & $0.839 \mathrm{~ns}^{\mathrm{a}}$ \\
\hline & BMI $\left(\mathrm{kg} / \mathrm{m}^{2}\right)$ & $24.9 \pm 4.0$ & $23.6 \pm 15.8$ & $0.373 \mathrm{~ns}^{\mathrm{a}}$ \\
\hline $\begin{array}{l}\text { Have had foot care } \\
\text { education before }\end{array}$ & Yes & $3(10.3)$ & $5(19.2)$ & \multirow[t]{2}{*}{$0.351 \mathrm{~ns}^{\mathrm{b}}$} \\
\hline \multirow{4}{*}{ Medication for diabetes } & No & $26(89.7)$ & $21(80.8)$ & \\
\hline & Yes & $21(72.4)$ & $17(65.3)$ & \multirow{4}{*}{$0.573 \mathrm{~ns}^{\mathrm{b}}$} \\
\hline & Internal use & $19(63.3)$ & $13(50.0)$ & \\
\hline & Insulin & $2(6.9)$ & $4(15.3)$ & \\
\hline \multirow{5}{*}{ Complications } & None & $8(27.6)$ & $13(50.0)$ & \\
\hline & Yes & $3(10.3)$ & $2(7)$ & \multirow{4}{*}{$0.733 \mathrm{~ns}^{\mathrm{b}}$} \\
\hline & Diabetic nephropathy & $2(6.9)$ & $2(7)$ & \\
\hline & Retinopathy & $1(3.4)$ & $0(0.0)$ & \\
\hline & None & $26(89.7)$ & $24(92.3)$ & \\
\hline
\end{tabular}

a: t-test; b: $\chi^{2}$-test; ns: not significant. 
the background particulars of the participants at the baseline. The mean age of the intervention group was $60.0 \pm 9.3$ years (17 males and 12 females), and that of the control group was $59.5 \pm 9.3$ years ( 14 males and 12 females). The duration of the disease of the intervention group was $2.2 \pm 1.4$ years and that of the control group was $2.0 \pm 1.1$ years. Three participants in the intervention group and 5 in the control group had experience of self-foot-care education. The majority of participants had been provided knowledge using the printed leaflet, but had no experience of self-foot-care education.

\subsection{Removal Rate of Skin Debris}

In the SFCEP and CEP groups, there were no statistically significant differences in the removal rate of skin debris after washing with warm water; however, there were significant differences after washing with soap $(\mathrm{p}<0.05)$ (Table 2). The vertical axis (columns) shows the removal rate after washing with soap and the horizontal axis (rows) shows the removal rate after washing with warm water. When washing with warm water, the number of participants with removal rates of $40 \%$ or below were $13(65 \%)$ in the SFCEP and 13 (86\%) in the CEP groups. After washing with soap, this (>40\%) was $1(5 \%)$ in the SFCEP and $6(40 \%)$ in the CEP groups. The maximum removal values in the SFCEP and CEP groups were $91 \%$ and $88 \%$.

In both groups the removal rates after washing with soap were higher than that after washing with warm water. For improvements, the participants in the SFCEP where the removal rate was lower showed more improvement than those with higher removal rates. These differences can be expressed by the following approximate expressions: $\mathrm{y}=8.39661 \mathrm{n}(\mathrm{x})+47.69, \mathrm{R}^{2}=0.5569$ (approximation degree) in the SFCEP group; and $y=14.1481 \mathrm{n}(\mathrm{x})+20.488, \mathrm{R}^{2}=0.4427$, where $\mathrm{x}$ is the removal rate after washing with warm water, and y with soap (Figure 2).

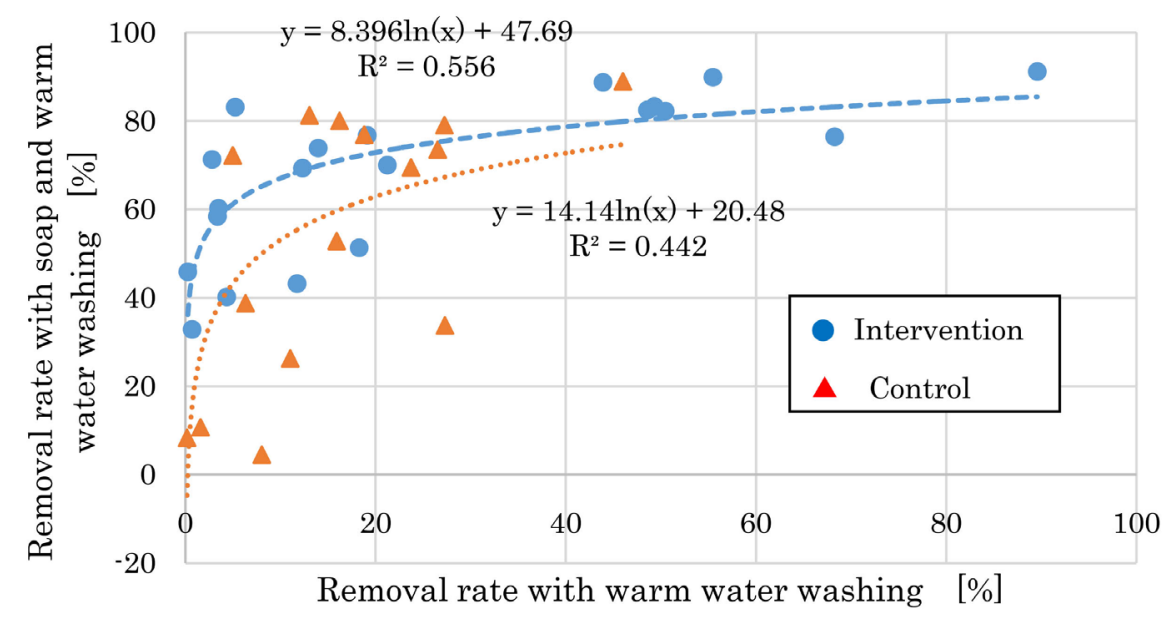

Figure 2. Comparison of the removal rate of skin debris of feet in 2 groups. Removal rate of foot stain = (area of fluorescence before washing - area of fluorescence after the washing)/area of fluorescence before washing $\times 100$. The area of fluorescence before washing is count as $100 \%$. The decrease in fluorescence was regarded as washing effect. 
Table 2. Comparison of 2 groups about cleaningness of feet (after 6 months).

\begin{tabular}{cccc}
\hline Cleaning method & $\begin{array}{c}\text { Intervention group } \\
(\mathrm{n}=20) \\
\text { Mean } \pm \mathrm{SD}\end{array}$ & $\begin{array}{c}\text { Control group } \\
(\mathrm{n}=15) \\
\text { Mean } \pm \mathrm{SD}\end{array}$ & p value \\
\hline Warm water only & $26.1 \pm 26.3$ & $16.5 \pm 29.9$ & $0.079 \mathrm{~ns}$ \\
Soap and warm water & $68.5 \pm 12.3$ & $53.1 \pm 17.8$ & $0.045^{\star}$ \\
\hline
\end{tabular}

t-test: ${ }^{*} \mathrm{p}<0.05$; ns: not significant.

\subsection{Symptoms and Conditions of the Feet}

The changes in the conditions of the feet of the participants at the 6th month for the SFCEP and CEP groups showed a significant difference in the dryness $(\mathrm{p}<$ $0.001)$, horny tissue incidence $(\mathrm{p}<0.01)$, and coldness of the feet $(\mathrm{p}<0.05)$ between the 2 groups (Table 3 ). There were no significant differences in callus, deep cut/ingrown toenails, numbness, ringworm. Further, as a result of the comparison between the SFCEP and CEP groups before and after the intervention, there were improvements in all items in the SFCEP group. Significant differences were specifically determined in the dryness $(p<0.01)$, horny tissue incidence $(\mathrm{p}<0.05)$, numbness $(\mathrm{p}<0.05)$, and peripheral coldness $(\mathrm{p}<0.01)$ only in the SFCEP group (Table 4).

\section{Discussion}

Self-foot-care education using the "self-foot-care educational program (SFCEP)" improved (reduced) the removal rate of skin debris, and the symptoms and conditions of the feet in the participants in the SFCEP group.

In the removal rate of skin debris, there was a significant difference in the removal rate after washing with soap, and the effectiveness of washing the feet was more significant in the SFCEP group. However, the removal rate after washing with soap in the CEP group varied between participants. These may illustrate the effect of the education that enables participants to acquire appropriate foot-care knowledge through self-foot-care and self-monitoring after the repeated instruction on how to wash and care for the feet.

The participants in the CEP group also improved the removal rate of skin debris, particularly around the nails and between toes by washing the feet with sufficient foam using soap, but $100 \%$ removal was not achieved. The findings suggest the importance of instructing patients to wash the feet carefully, around and between toes using soap, to keep the feet clean.

For the symptoms and conditions of the feet, the SFCEP group improved more than the CEP group in dryness and coldness of the feet. Horny tissue incidence, calluses, deep cuts/ingrown toenails, numbness, and ringworms showed no significant differences between the two groups, but the SFCEP group showed more improvement than the CEP group. Comparing the self-foot-care behaviors, the SFCEP group was more regular in the effort to wash, moisturize, and massage the feet with cream as a result of observing the foot conditions, such as 
Table 3. Comparison of 2 groups about symptoms and conditions of feet (after 6 months).

\begin{tabular}{cccc}
\hline Symptoms and conditions of the feet & $\begin{array}{c}\text { Intervention group } \\
(\mathrm{n}=29) \\
\mathrm{n}(\%)\end{array}$ & $\begin{array}{c}\text { Control group } \\
(\mathrm{n}=26) \\
\mathrm{n}(\%)\end{array}$ & p value \\
\hline Dryness & $0(0.0)$ & $23(88.5)$ & $1.9340^{* * *}$ \\
Horny tissue & $5(17.2)$ & $15(57.7)$ & $0.0050^{* *}$ \\
Callus & $9(31.0)$ & $8(30.8)$ & $0.9830 \mathrm{~ns}$ \\
Deep cut/ingrown toenail & $0(0.0)$ & $4(15.4)$ & $0.0940 \mathrm{~ns}$ \\
Numbness & $3(10.3)$ & $4(15.4)$ & $0.8770 \mathrm{~ns}$ \\
Peripheral coldness & $1(3.4)$ & $8(30.8)$ & $0.0180^{*}$ \\
Ringworm & $1(3.4)$ & $6(23.1)$ & $0.0760 \mathrm{~ns}$ \\
\hline
\end{tabular}

$\chi^{2}$-test: ${ }^{*} \mathrm{p}<0.05,{ }^{* *} \mathrm{p}<0.01,{ }^{* * *} \mathrm{p}<0.001 ;$ ns: not significant.

Table 4. Comparison of the symptoms and conditions of the feet of the 2 groups (before and after 6 months).

\begin{tabular}{ccccccc}
\hline & \multicolumn{3}{c}{ Intervention $(\mathrm{n}=29)$} & \multicolumn{3}{c}{ Control (n=26) } \\
& \multicolumn{3}{c}{$\mathrm{n}(\%)$} & & $\mathrm{n}(\%)$ \\
\cline { 2 - 7 } & Before & 6 months & p value & Before & 6 months & p value \\
\hline Dryness & $26(89.7)$ & $0(0.0)$ & $0.000^{* *}$ & $24(92.3)$ & $23(88.5)$ & $1.000 \mathrm{~ns}$ \\
Horny tissue & $13(44.8)$ & $5(17.2)$ & $0.047^{*}$ & $15(57.7)$ & $15(57.7)$ & $0.779 \mathrm{~ns}$ \\
Callus & $15(51.7)$ & $9(31.0)$ & $0.183 \mathrm{~ns}$ & $8(30.8)$ & $8(30.8)$ & $0.764 \mathrm{~ns}$ \\
Deep cut/ingrown toenail & $3(10.3)$ & $0(0.0)$ & $0.236 \mathrm{~ns}$ & $4(15.4)$ & $3(11.5)$ & $1.000 \mathrm{~ns}$ \\
Numbness & $11(37.9)$ & $3(10.3)$ & $0.032^{*}$ & $4(15.4)$ & $4(15.4)$ & $0.701 \mathrm{~ns}$ \\
Peripheral coldness & $12(41.4)$ & $1(3.4)$ & $0.002^{* *}$ & $8(30.8)$ & $8(30.8)$ & $0.764 \mathrm{~ns}$ \\
Ringworm & $4(13.8)$ & $1(3.4)$ & $0.349 \mathrm{~ns}$ & $6(23.1)$ & $6(23.1)$ & $0.742 \mathrm{~ns}$ \\
\hline
\end{tabular}

$\chi^{2}$-test: ${ }^{*} \mathrm{p}<0.05,{ }^{* *} \mathrm{p}<0.01 ; \mathrm{ns}$ : not significant.

nails, calluses, and dryness. This suggests that these behaviors may lead to the improvements in the symptoms and conditions of the feet.

Daily foot-care to keep the feet clean is the basis for prevention of the type 2 diabetes foot disease. It is reported that calluses developing on the soles of feet and toes need regular care because these symptoms increase the probability of foot ulcers [13]. Ohta and Murakami [14] reported that the removal of horny tissue is effective to improve sensory input. Honda et al. [15] stated that massage by foot bathing will improve the ankle flexibility and blood circulation. These findings suggest that the improvement of the removal rate of skin debris and the symptoms and conditions of the feet may contribute to the long-term prevention of diabetic foot disease. In the education program here, we conducted the practical instruction three times, but whether the three times is an appropriate number of interventions has to be verified. It is important to provide foot-care education in the early stage after the diagnosis of type 2 DM because it is too late 
when patients are in a high-risk condition. We may expect positive economic effects of the medical treatment if complications such as foot gangrene are prevented by preventing type 2 diabetic foot disease.

\section{Limitations and Remaining Issues}

This study is an intervention study focusing on patients with type $2 \mathrm{DM}$ at a facility, and the number of facilities and participants may not represent the general population. Due to this limitation, it is necessary to collect more evidence by expanding the locations where the program is introduced, such as including the home environment in addition to hospitals, and by evaluating the effectiveness and validity of the SFCEP.

\section{Conclusion}

The "self-foot-care educational program (SFCEP)" which provides individualized, repeated and practical instruction in "self-foot-care" and "self-monitoring" improves the removal rate of skin debris, and the symptoms and conditions of the feet of the participants. Continuing this education will make it possible to prevent type 2 diabetes foot disease. The findings suggest that the SFCEP, which encourages patients with type $2 \mathrm{DM}$ to act to prevent foot disease, may be effective in the prevention of development and deterioration of diabetes-induced foot disease.

\section{Acknowledgements}

We wish to express our gratitude for the cooperation provided by the patients and medical experts in the participating facilities.

\section{Conflicts of Interest}

The authors declare no conflicts of interest regarding the publication of this paper.

\section{References}

[1] Shinjo, T. (2000) Foot Care for Patients with Diabetes. Ishiyaku Publishers, Tokyo. (In Japanese)

[2] Yokota, K. and Doi, Y. (2008) Thought in Patients with Lower Limb Amputation Due to Peripheral Circulatory Disorder. Journal of Japanese Society for Chronic Illness and Conditions Nursing, 2, 49-56. (In Japanese)

[3] Singh, N., Armstrong, D.G. and Lipsky, B.A. (2005) Preventing Foot Ulcers in Patients with Diabetes. Journal of the American Medical Association, 293, 217-228. https://doi.org/10.1001/jama.293.2.217

[4] Yokota, K. (2018) Foot Care Education for Adult Patients with Diabetes: A Literature Review. Osaka Medical College of Nursing Research, 8, 108-115.

[5] Frank, K.L. (2003) Self-Management of Foot Care for Patients 65 Years of Age or Older with Diabetes. Indiana University, Bloomington, 1-149.

[6] Borges, W.J. and Ostwald, S.K. (2008) Improving Foot Self-Care Behaviors with 
Pies Sanos. Western Journal of Nursing Research, 30, 325-341. https://doi.org/10.1177/0193945907303104

[7] Lincoin, N.B., Radford, K.A., Game, F.L. and Jeffcoate, W.J. (2008) Education for Secondary Prevention of Foot Ulcers in People with Diabetes: A Randomized Controlled Trial. Diabetologia, 51, 1954-1961.

https://doi.org/10.1007/s00125-008-1110-0

[8] Yamamoto, Y. (2014) An Education Program Based on the Health Belief Model for Newly Diagnosed Type 2 Diabetes Patients to Promote Self-Care Behaviors. Doctoral Dissertation, Osaka Prefecture University, Osaka. (In Japanese)

[9] Mori, K. (2014) Effectiveness of Program for Encouraging Self-MonitoringAwareness of Symptoms of Respiratory Infection and Influence on Behavior toward the Symptoms. UH CNAS, RINCPC Bulletin, 21, 51-63. (In Japanese)

[10] Kinjyo, T., Kobayashi, S., Kiyohara, F., Fujimoto, K. and Kanda, K. (2015) Analysis of the Self-Monitoring Intervention Study for Improvement of the Symptoms. Annals of Gunma University Graduate School of Health Sciences, 36, 83-96. (In Japanese)

[11] Ozaki, K., Kazawa, K. and Moriyama, M. (2017) Comparison of Remote Education with Direct Education and Evaluation of Feasibility in Patients with Diabetic Nephropathy: 12-Month Follow-Up. Journal of Japan Academy of Diabetes Education and Nursing, 21, 46-55. (In Japanese)

[12] Ahmad Sharoni, S.K., Minhat, H.S., Mohd Zulkefli, N.A. and Baharom, A. (2016) Health Education Programmes to Improve Foot Self-Care Practices and Foot Problems Among Older People with Diabetes: A Systematic Review. International Journal of Older People Nursing, 11, 214-239. https://doi.org/10.1111/opn.12112

[13] Murray, H.J., Young, M.J., Hollis, S. and Boulton, A.J.M. (1996) The Association Between Callus Formation, High Pressures and Neuropathy in Diabetic Foot Ulceration. Diabetic Medicine, 13, 979-982.

[14] Ohta, K. and Murakami, M. (1976) Aging of the Nerves and Mind. Igaku-Shoin Ltd., Tokyo. (In Japanese)

[15] Honda, Y., Aso, Y., Ibe, A., Tamaru, T. and Katayama, M. (2010) Effect of Footbaths on Elderly Women's Walking Ability to Prevent Falls. Journal of Japan Health Medicine Association, 19, 70-75. (In Japanese) 